\title{
Pharyngeal airway changes following symohyseal distraction osteogenesis
}

\section{Original Article}

Dina Elabbasy

${ }^{1}$ Department of Orthodontics, Faculty of Dentistry, Cairo University, Cairo, Egypt

\begin{abstract}
Introduction: The aim of this study was to analyze the effects of mandibular symphyseal distraction osteogenesis (MSDO) on the pharyngeal airway dimensions in a group of adult patients.

Subjects and Methods: The sample consisted of digital lateral cephalograms of 10 patients ( 7 females and 3 males) with a mean age of $21.0 \pm 2.5$ years. Radiographs were taken before start of distraction (T1) and following distraction (T2) (12.5 days \pm 2.3 days after surgery). Symphyseal distraction was done using a bone-borne distractor. The mean value of mandibular symphyseal distraction was $8.4 \pm 1.7 \mathrm{~mm}$. Digital lateral cephalometric tracing was done to evaluate airway changes following symphyseal distraction.

Results: Digital lateral cephalometric analysis revealed no statistically significant changes in nasopharyngeal airway $(0.3 \pm 0.1 \mathrm{~mm})(P>0.05)$. There were statistically significant changes in oropharyngeal and hypopharyngeal airway widths $(1.2 \pm 0.3 \mathrm{~mm})$ and $(0.7 \pm 0.4 \mathrm{~mm})$ respectively $(P<0.01)$. Hyoid bone position showed insignificant changes for the value Walker P-H $(-1.1 \pm 0.2 \mathrm{~mm})$ and H-RGN $(-0.9 \pm 0.4 \mathrm{~mm})(P>0.05)$ while statistically significant decrease were evident for the vertical measurement H-C3RGN $(-1.2 \pm 0.2 \mathrm{~mm})(P<0.01)$.

Conclusion: The results propose that MSDO significantly affects the lower pharyngeal airway dimensions but has no effect on the upper pharyngeal airway measurements. No significant effects on hyoid bone position were observed except mild decrease of its vertical measurement to reference planes. The normal reflex mechanisms that conserve the patency of the airway may have negated any potential changes in the hyoid bone position.
\end{abstract}

Key Words: Airway changes, Mandibular anterior crowding, Midsymphyseal distraction osteogenesis, Symphyseal distraction, Transverse mandibular deficiency.

Received: 02 September 2019, Accepted: 14 October 2019.

Corresponding Author: Dina Elabbasy, Department Orthodontics, Faculty of Dentistry, Cairo University, Cairo, Egypt, Tel.: +201001408066, E-mail: dinaosman@hotmail.com.

ISSN: 2090-097X, April 2019, Vol. 10, No. 2

\section{INTRODUCTION}

Distraction osteogenesis (DO) is a method of generating new bone following a corticotomy or an osteotomy and incremental traction with gradual separation of the bony segments ${ }^{[1]}$. The distraction gap then gets filled with newly formed bone $e^{[2-4]}$. The tension-stress principle advocated by the russian orthopedic surgeon Illizarov in the $1960 \mathrm{~s}$ is the foundation of this mechanism. This technique was especially useful in limb lengthening and elongation of long bones. Its applications also involve craniofacial reconstruction $^{[5]}$ such as lengthening of the mandible in patients with hemifacial microsomia ${ }^{[6]}$.

Widening of the mandible by rapid surgical expansion to correct transverse deficiencies of the mandible has been originated by Guerrero, 1990 $0^{[7]}$ and later implemented by Santo et al, $2000^{[8]}$ who utilyzed symphyseal tooth- and bone-borne distractors to successfully treat transverse deficiencies instead of orthognathic surgery. This is advantageous as it avoids the need for dental extractions and/or jeopardized periodontal or functional complications $^{[9]}$.

Different types of distractors can be used for symphyseal distraction: bone-borne, tooth-borne or hybrid appliance $^{[10-13]}$. Each has its own benefits and limitations. Mechanically, bone-borne distractors provide the best results as the forces are transmitted directly to the bone and result in parallel basal mandibular bone widening and stable results ${ }^{[11,14,15]}$. Drawbacks include high cost and need of an invasive operation for placement and removal of the distractor. On the other hand, tooth-borne and hybrid distractors are less invasive and cheaper, but do not yield pure skeletal results. They mostly yield larger dentoalveolar expansion with dental tipping ${ }^{[11,16,17]}$.

Airway parameters might be easily altered as a consequence of separation of the two mandibular halves. The hyoid bone is an important structure sustained by muscles and ligaments and acts as a functional interface between structures of the mandible, larynx, cranium as 
well as the airway passages confined by these structures. Therefore, due to closeness of the hyoid bone to the pharyngeal airway, any changes in its position due to orthodontic or surgical treatment can have significant functional effects ${ }^{[18]}$.

Past studies revealed that changes in mandibular position also alter the position of the hyoid bone ${ }^{[19,20]}$. The hyoid bone adapts to changes in the head and cervical posture. Previous studies stated that the relationship between the hyoid bone and cervical structures is more stable than the one with the mandible and the cranium ${ }^{[21]}$.

The hyoid bone is connected to the pharynx, mandible, and cranium through muscles and ligaments. It is the only bone of the body that has no bony articulations. The hyoid bone and its connecting muscles are also part of the oropharyngeal complex ${ }^{[21]}$. The separation of the two mandibular halves can alter the pharyngeal airway dimensions as well as tongue and positions of the hyoid bone. The hyoid bone position is relatively constant within the individual throughout growth periods. It tends to preserve its relative position to the mandible from the age of three years ${ }^{[22]}$. The position and function of the hyoid bone in response to orthodontic, orthopedic and orthognathic procedures has been previously studied by
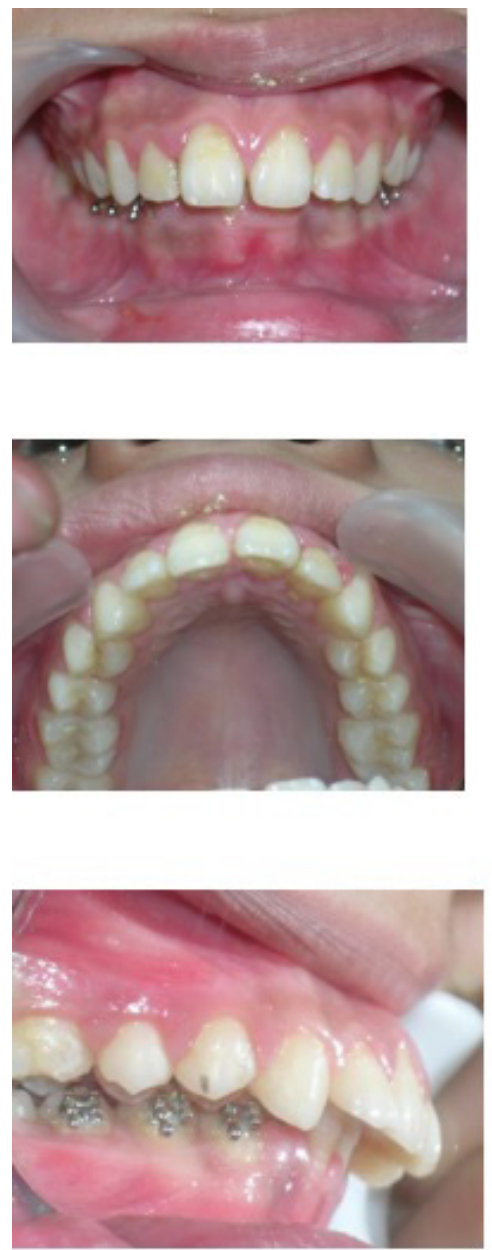

several authors. For example in surgical correction of mandibular prognathism, mandibular setback resulted in changes in hyoid bone position which moved inferiorly and posteriorly ${ }^{[19,20,23]}$. Moreover, the distance between the posterior border of the mandibular symphysis and the body of the hyoid bone decreased. However, the distance between the hyoid bone and the vertebral column showed minimal changes. This led to the hypothesis that certain physiologic mechanisms exist which prevent impingement upon the pharyngeal airway.

Inspite of the presence of many reports in the literature investigating the effects of MSDO skeletally and dentally ${ }^{[8]}$ no studies on the effects of symphyseal distraction on pharyngeal airway dimensions are available. Hence, this study was conducted to evaluate the effects of MSDO on the pharyngeal airway dimensions.

\section{SUBJECTS AND METHODS}

This study was performed by analyzing the lateral cephalometric radiographs of 10 patients ( 7 females and 3 males) who underwent mandibular symphyseal distraction osteogenesis with a mean age $21.0+-2.5$ years obtained at T1(before start of distraction) and at T2 (after symphyseal distraction). Patients included in the study had the following criteria: (Figure 1).
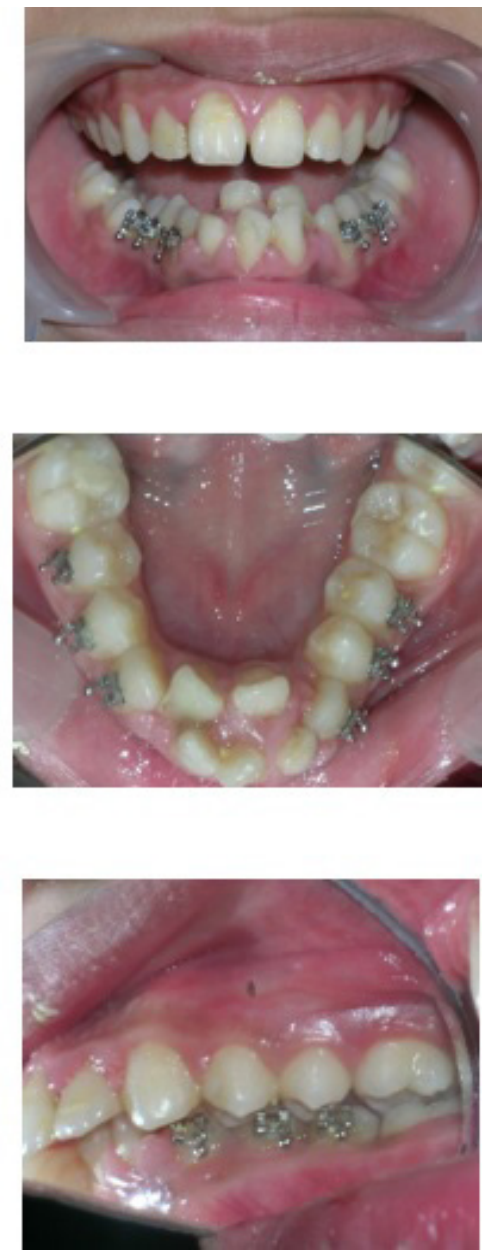

Figure 1: Showing pretreatment intraoral photos of a patient with bilateral posterior scissorbite. 
- $\quad \mathrm{V}$-shaped mandible with severe mandibular arch crowding a minimum of $10 \mathrm{~mm}$ and well aligned upper teeth combined with unilateral or bilateral posterior scissorbite.

- Full orthodontic records especially lateral cephalometric radiographs taken in habitual occlusion after the patient had swallowed (to avoid functional alteration of hyoid bone position).

- No periodontal diseases or TMJ disorder.

- No previous orthodontic treatment.

- No respiratory problems or nasal obstructions.

- No past surgeries such as tonsillectomy for both groups.

- No syndromes, systemic illnesses, dental anomalies.

Orthodontic records included photographs, study models and radiographs (digital panorama and lateral cephalometric radiographs).

The procedure and surgical operation has been explained to the patients and a consent form has been signed. Research has been approved by the institutional ethics committee.

Fixed orthodontic appliances were inserted in the lower arch followed by the upper arch (preadjusted appliances, Roth 0.022 x 0.028 inches) (Ormco, West Collins, Ca-USA). Root divergence (at least $3 \mathrm{~mm}$ ) of the lower central and lateral incisor brackets was done by inclining the brackets angulations distally or placing a V-bend in the wire. Periapical radiographs were used to detect the root approximation of the lower central and lateral incisors to decide on the most suitable site for the interdental osteotomy depending on the presence of adequate bone.

The symphyseal distraction carried out for the patients was performed with a bone-borne distractor (Rotterdam Midline Distractor, Kls Martin, Germany) (Figure 2) using the modified technique previously described by ${ }^{[24]}$. All distractors had a range of $15 \mathrm{~mm}$. Activation started after a latency period of 7 days following the surgery. It was done at a rate of $0.25 \mathrm{~mm}$ expansion per 90 degrees turn for a total of $1 \mathrm{~mm} /$ day $^{[11,25,26,27]}$. The activations were done twice a day, once in the morning and once in the evening, 2 turns per each activation. The total amount of distraction required was determined based on the amount of space needed to relieve the crowding and correct the transverse discrepancy of the maxillomandibular relationship. The surgical operation was performed by the same oral surgeon.

Lateral cephalometric landmarks and measurements for assessment of the pharyngeal airway and hyoid bone position were as follows: (Figure 3).

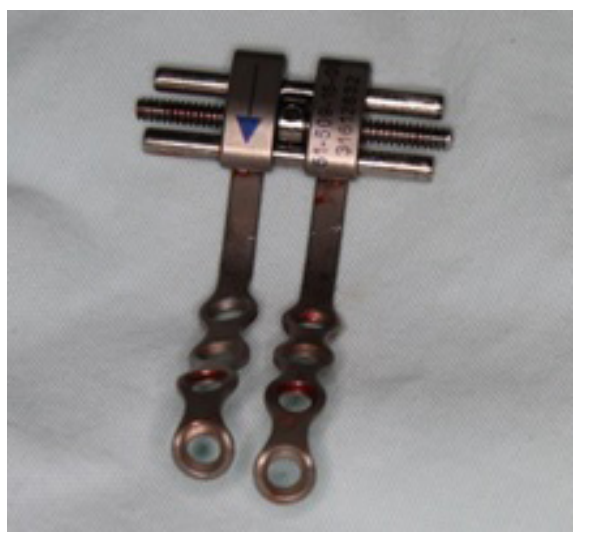

Figure 2: Rotterdam midline distractor.

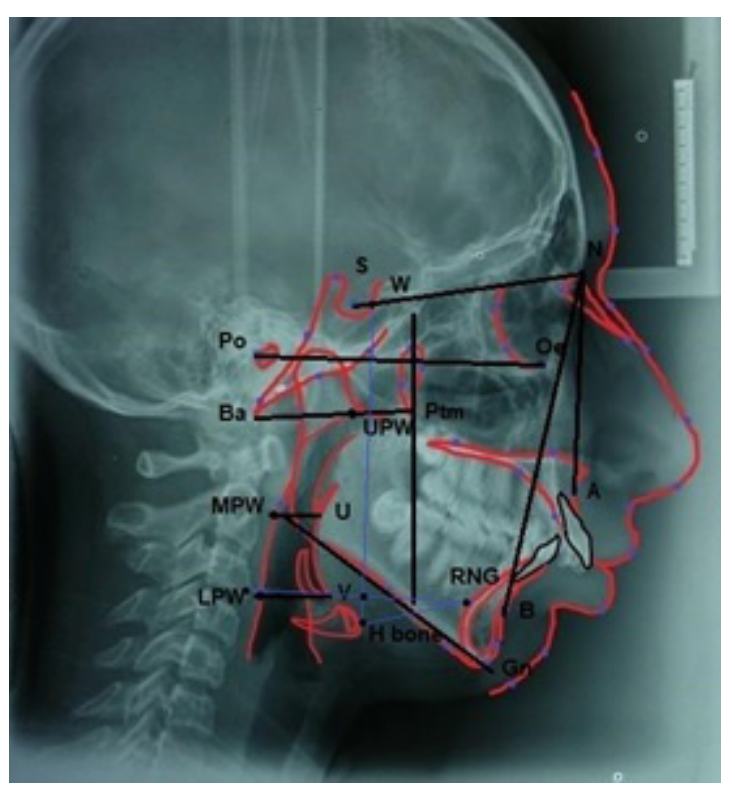

Figure 3: Showing pretreatment digital lateral cephalometric xray with reference planes and landmarks for the pharyngeal airway and hyoid bone measurements:

Ptm: pterygomaxillary fissure; Ptm vertical: a vertical line passing through Ptm perpendicular to Frankfurt horizontal; Ba: Basion; U: Uvula; V: Vallecula; UPW: Upper pharyngeal width and is formed by intersection of the line Ptm-Basion with posterior pharyngeal wall perpendicular on Ptm vertical; MPW: Middle pharyngeal width which is the horizontal distance between the Uvula and intersection with the posterior pharyngeal wall perpendicular to Ptm vertical; LPW: Lower pharyngeal width which is the horizontal distance between the Vallecula and the intersection with the posterior pharyngeal wall perpendicular to Ptm vertical; Walker P-H (mm), the vertical distance of the hyoid bone to the Walker point; H-C3RGN (mm): the vertical distance of the hyoid bone to the line connecting points $\mathrm{C} 3$ (third cervical vertebrae) and retrognathion (the most prominent point of mandibular symphyseal posterior border; H-RGN (mm): the horizontal distance from the hyoid bone to retrognathion. 

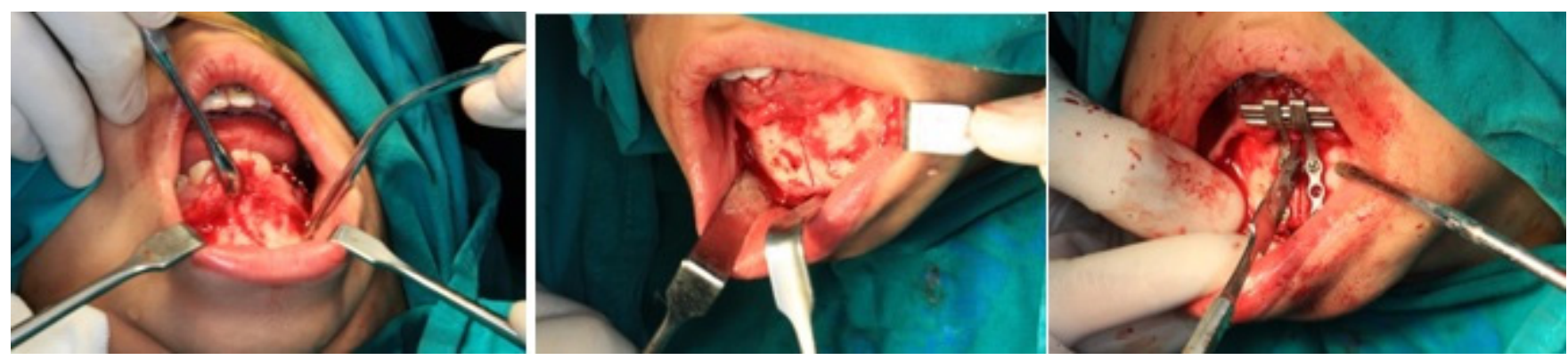

Figure 4: Showing the surgical osteotomy procedure for placement of the distractor.

\section{Statistical Methods:}

All Data were collected, tabulated and subjected to statistical analysis. Statistical analysis was performed by SPSS in general (version 17), while Microsoft office Excel was used for data handling and graphical presentation.

Quantitative variables were described by the Mean, Standard Deviation (SD), the Range (Minimum Maximum), Standard Error (SE) and $95 \%$ confidence interval of the mean.

Qualitative categorical variables were described by proportions and Percentages.

Shapiro-Wilk test of normality was used to test normality hypothesis of all quantitative variables for further choice of appropriate parametric and non parametric tests. Mostly the variables were found normally distributed allowing the use of parametric tests. Paired samples t test was used for comparing the Post and Pre within the study group.

Significance level was considered at $P \leq 0.05$ (S); while for $P \leq 0.01$ was considered highly significant (HS). Two Tailed tests were assumed throughout the analysis for all statistical tests.

\section{RESULTS}

A good clinical outcome was obtained in all subjects. Distraction was successful and the required amount of expansion was achieved with a mean bony distraction value of $(10.43 \mathrm{~mm})$. The distraction gap was symmetric (Figure 5). Widening of the lower arch was evident and elimination of the arch length discrepancy without the need for dental extraction was obtained (Figure 6). A good occlusal outcome was obtained and proper interdigitation was achieved with elimination of the posterior scissorbite. Overjet and overbite were significantly improved with a reduction of the overjet from $10 \mathrm{~mm}$ to $5 \mathrm{~mm}$ and correction of the overbite to around $30 \%$ were attained.
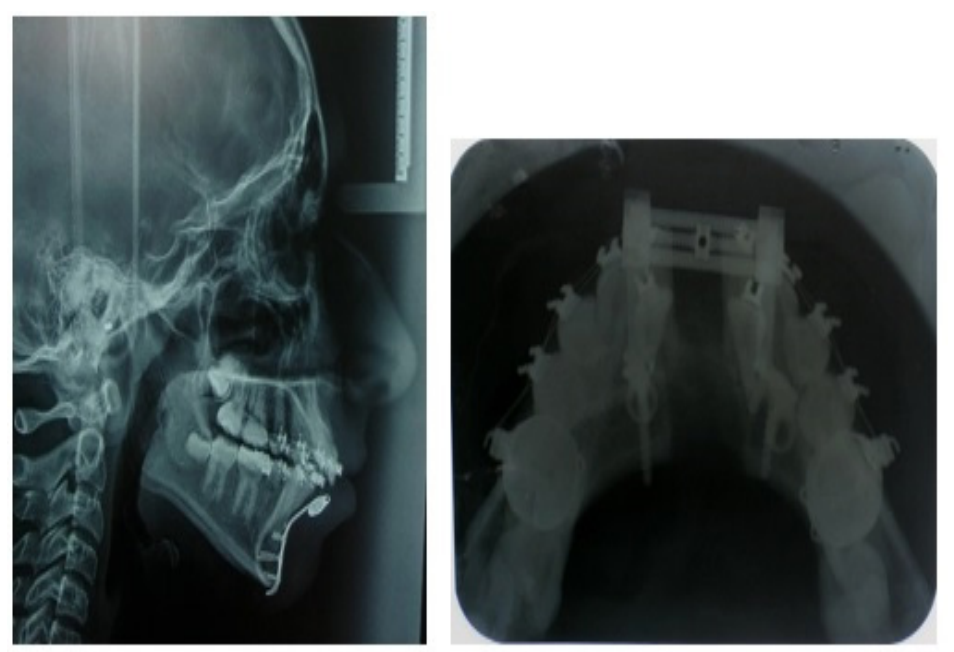

Figure 5: Lateral cephalometric radiograph and occlusal radiograph at the end of distraction.

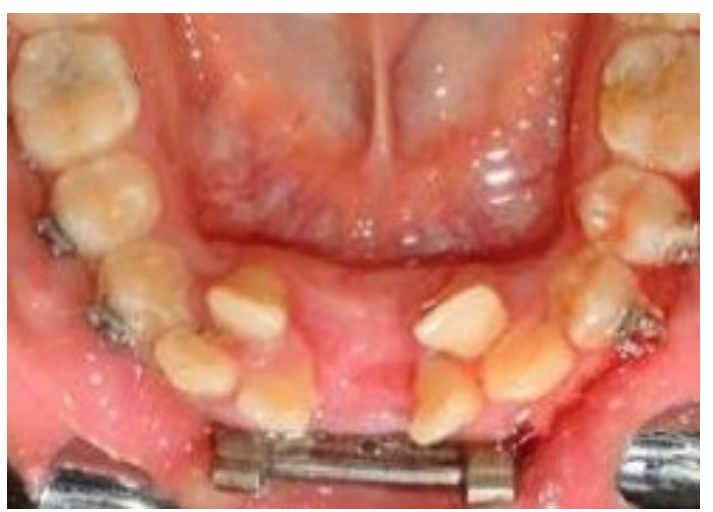

Figure 6: Clinical photograph showing the lower diastema at the end of distraction. 
As shown in (Table 1), regarding airway measurements, no statistically significant differences were observed for nasopharyngeal or upper pharyngeal airway dimensions (UPW) $(P>0.05)$. Statistically significant increases were recorded for both oropharyngeal or middle pharyngeal airway $(\mathrm{MPW})(P \leq 0.01)$ and hypopharyngeal airway or lower pharyngeal airway (LPW) $(P \leq 0.01)$.

Regarding hyoid bone measurements, statistically insignificant changes were recorded for the vertical measurement (Walker P-H) $(P>0.05)$ and horizontal distance between hyoid bone and retrognathion (H-RGN), whereas statistically significant decrease was recorded for the vertical distance between the hyoid bone and a horizontal line joining cervical vertebra 3 and retrognathion (H-C3RGN) $(P \leq 0.05)$.

Table 1: Pharyngeal airway and hyoid bone measurements at T1 and $\mathrm{T} 2$ showing mean changes and level of significance:

\begin{tabular}{|c|c|c|c|c|c|c|}
\hline \multirow[b]{2}{*}{$\begin{array}{l}\text { Pharyngeal airway } \\
\text { and Hyoid bone } \\
\text { measurements } \\
(\mathrm{mm})\end{array}$} & \multicolumn{2}{|c|}{ T1 } & \multicolumn{2}{|c|}{ T2 } & \multirow{2}{*}{$\begin{array}{l}\text { M e a n } \\
\text { changes }\end{array}$} & \multirow[t]{2}{*}{ P-Value } \\
\hline & Mean & SD & Mean & SD & & \\
\hline UPW & 14.2 & 5.4 & 14.5 & 5.7 & $0.3 \pm 0.1$ & NS \\
\hline MPW & 9.3 & 3.2 & 10.5 & 3.1 & $1.2 \pm 0.3$ & $0.005^{*}$ \\
\hline LPW & 9.6 & 3.1 & 10.3 & 3.0 & $0.7 \pm 0.4$ & $0.003 *$ \\
\hline Walker P-H & 109.8 & 11.8 & 108.8 & 12.5 & $-1.1 \pm 0.2$ & NS \\
\hline H-C3RGN & 14.3 & 5.4 & 13.1 & 6.5 & $-1.2 \pm 0.2$ & $0.007 *$ \\
\hline H-RGN & 38.6 & 6.5 & 37.7 & 5.9 & $-0.9 \pm 0.4$ & NS \\
\hline
\end{tabular}

$P>0.05(\mathrm{NS}),{ }^{*} P \leq 0.05,{ }^{* *} P \leq 0.01$.

\section{DISCUSSION}

Minor transverse mandibular discrepancies are corrected by orthodontic dental arch expansion, extraction or interproximal dental stripping, whereby severe mandibular transverse discrepancies entail surgical intervention due to the early synostosis of the mandibular midline suture $^{[28-30]}$. Surgical transverse mandibular widening with lateral rotation of the two mandibular halves and grafting is predictable for treatment of moderate discrepancies. Nonetheless, it is contraindicated in cases with severe transverse mandibular discrepancies due to high risk of periodontal complications and relapse tendency ${ }^{[11,31]}$.

It is a well-known fact that orthopedic mandibular expansion is impossible due to the very premature synostosis of the mandibular midline suture. Orthodontists are therefore challenged with two options: orthodontic expansion but this carries a periodontal risk or undergoing other means of space gaining by extraction or interdental stripping. Mandibular symphyseal distraction provides a different prospect in that the discrepancy can be corrected by simultaneously expanding both the dentoalveolar and the basal bone levels. An intentional surgical bone fracture is made after which progressive traction of the two mandibular halves is initiated. This provides mechanical stimulation for new bone formation. This new bone formation leads to successful increase of the inter-canine width with no risk of relapse ${ }^{[32]}$.

The hyoid bone forms the anterior limit of the pharyngeal airway space. Thus, the position of hyoid bone and position of tongue can be considered determinants of pharyngeal airway space.

The hyoid bone is attached by the suprahyoid and infrahyoid muscles to the mandibular, cranial and laryngeal structures. Its location is in close proximity to the pharyngeal airways. Moreover, it adapts its position under natural circumstances to accommodate alterations in head posture and cervical spine inclination and thus inflicts vital physiologic consequences. Therefore, a good understanding of the elements affecting its position is fundamental in perceiving the effects of orthognathic surgical mandibular procedures, orthopedic treatment as well as influences on obstructive sleep apnea ${ }^{[18]}$.

To our knowledge, no previous studies have investigated the effects of mandibular symphyseal distraction osteogenesis persee on the pharyngeal airway dimensions except one by Malkoc et al. ${ }^{[33]}$ who evaluated the combined effects of MSDO and rapid palatal expansion (RPE) in patients with constricted maxillary and mandibular arches. Their results showed that MSDO causes small changes in the pharyngeal airway measurements or the hyoid bone position in adult patients.

The sample in this study included 10 patients with a mean age of 21.0 years (range, 15.5 - 25.7 years); consequently, no significant growth changes were anticipated. Lateral cephalometric radiographs have repeatedly been used for evaluating dentofacial structures as well as the pharyngeal airway with considerable accuracy and reproducibility ${ }^{[34-36]}$. Therefore, they were used in this study as a means of evaluation of the airway structural changes that follow symphyseal distraction osteogenesis.

Airway changes were measured according to the method previously described by Jena et $a l^{[37]}$ to quantify changes in the nasopharyngeal, oropharyngeal and hypopharyngeal airways. No consideration was given for measuring the distance between the hyoid bone and the vertebral column as any slight variation in patient's posture could change the vertebral position and hence result in significant error. Therefore, this measurement would be regarded as unreliable.

As previously reported in past studies by Wolk ${ }^{[23]}$ with posterior mandibular movements the hyoid apparatus moves inferiorly but is stable anteroposteriorly. Therefore the functional integrity of the airway is maintained through morphologic adaptation. The vertical position of the hyoid bone was evaluated relative to Walker point and not the mandibular plane as any changes in the mandibular plane angle due to treatment would falsely affect this measurement. 


\section{CONCLUSIONS}

MSDO is an effective technique to correct transverse mandibular deficiency and resolve dental crowding without the need for extraction. It is a procedure that also improves esthetics and provides good stability without adverse side effects. It positively influences the lower pharyngeal airway and results in increased airway patency which could be used to improve the symptoms for patients with obstructive sleep apnea. However, it has no influence on the hyoid bone position.

\section{Recommendations}

Future studies including more subjects and evaluating the effects of MSDO on the long-term should be carried out.

\section{Acknowledgements}

Special thanks to Dr. Salaheldin ElAbbasy, lecturer in the department of Oral and Maxillofacial Surgery, Cairo University for his great help and support in performing the oral surgical procedures in this study.

\section{CONFLICT OF INTEREST}

There are no conflicts of interest.

\section{REFERENCES}

1. Ilizarov GA. The tension-stress effect on the genesis and growth of tissues: part I. The influence of stability of fixation and soft tissue preservation. Clin Orthop Relat Res 1989;238:249-81.

2. Peltonen JI, Kahri AI, Lindberg LA, Heikkila PS, Karaharju EO, Aalto KA. Bone formation after distraction osteotomy of the radius in sheep. Acta Orthop Scand 1992;63:599-603.

3. Sproul JT, Price CT. Recent advances in limb lengthening. Part 2: biological advances. Orthop Rev 1992;21:425-30.

4. Windhager R, Tsuboyama T, Siegl H, Groszschmidt $\mathrm{K}$. Effect of bone cylinder length on distraction osteogenesis in the rabbit tibia. J Orthop Res 1995;13:620-8.

5. Snyder CC, Levine GA. Mandibular lengthening by gradual distraction. Plast Reconstr Surg 1973;51:506-8.

6. Havlik RJ, Bartlett SP. Mandibular distraction lengthening in the severely hypoplastic mandible: a problematic case with tongue aplasia. J Craniomaxillofac Surg 1994;5:305-10.

7. Guerrero CA. Expansion mandibular quirurgica. Rev Venez Ortod 1990;48:1-2.
8. Santo MD, Guerrero CA, Bushang PA, English JD, Samchukov ML, Bell WH. Long-term skeletal and dental effects of mandibular symphyseal distraction osteogenesis. Am J Orthod Dentofacial Orthop 2000;118:485-93.

9. Constanti G, Guerrero C, Rodriguez AM, Legan HL. Mandibular widening by distraction osteogenesis. J Clin Orthop 2001; 35:165-73.

10. Iseri H, Malkoç S. Long-term skeletal effects of mandibular symphyseal distraction osteogenesis. An implant study.Eur J Orthod. 2005 ;27:512-7.

11. Alkan A, Ozer M, Baș B, Bayram M, Celebi N, Inal S, Ozden B. Mandibular symphyseal distraction osteogenesis: review of three techniques. Int J Oral Maxillofac Surg. 2007;36:111-7.

12. Boccaccio A, Cozzani M, Pappalettere C. Analysis of the performance of different orthodontic devices for mandibular symphyseal distraction osteogenesis. Eur J Orthod. 2011;33:113-20.

13. de Gijt JP, Vervoorn K, Wolvius EB, Van der Wal KG, Koudstaal MJ. Mandibular midline distraction: a systematic review. J Craniomaxillofac Surg. 2012;40:248-60.

14. Raoul G, Wojcik T, Ferri J. Outcome of mandibular symphyseal distraction osteogenesis with boneborne devices.J Craniofac Surg. 2009;:488-93.

15. Garreau É, Wojcik T, Rakotomalala H, Raoul G, Ferri J. Symphyseal distraction in the context of orthodontic treatment:a series of 35 cases. Int Orthod. 2015;13:81-95.

16. Niculescu JA, King JW, Lindauer SJ. Skeletal and dental effects of tooth-borne versus hybrid devices for mandibular symphyseal distraction osteogenesis. Angle Orthod. 2014 ;84:68-75.

17. Nadjmi N, Stevens S, Van Erum R. Mandibular midline distraction using a tooth-borne device and a minimally invasive surgical procedure. Int J Oral Maxillofac Surg. 2015;44:452-4.

18. Graber LW. Hyoid changes following orthopedic treatment of mandibular prognathism. Angle Orthod. 1978;48:33-8.

19. Takagi Y, Gamble JW, Profitt WR, Christiansen RL. Postural change of the hyoid bone following ostectomy of the mandible. Oral Surg Oral Med Oral Path. 23: 688-292, 1967.

20. Fromm B, Lundberg M. Postural behavior of the hyoid bone in normal occlusion before and after surgical correction of mandibular protrusion. Svensk Tandlak Tidskr 1970;63: 425-433. 
21. Biby, R. E. and C. B. Preston . The hyoid triangle. Am J Orthod Dentofac Orthop.1981. 80:92-97.

22. Durzo CA, Brodie AG. Growth behavior of the hyoid bone. Angle Orthod., 32:193-204, 1962.

23. Wolk RS. A cinefluorographic electromyographic and myometric study of muscular activity during swallowing in patients with mandibular resection. Unpublished Master's Thesis. 1969 Loyola University, Maywood, Ill.

24. Guerrero CA, Bell WH, Contasti GI, Rodriguez AM. Mandibular widening by intraoral distraction osteogenesis. Br J Oral Maxillofac Surg. 1997; $35: 383-392$.

25. Del Santo M Jr, Guerrero CA, Buschang PH, English JD, Samchukov ML, Bell WH. Longterm skeletal and dental effects of mandibular symphyseal distraction osteogenesis. Am J Orthod Dentofacial Orthop. 2000;118:485-93.

26. Malkoç $\mathrm{S}$, Işeri $\mathrm{H}$, Karaman $\mathrm{AI}$, Mutlu $\mathrm{N}$, Küçükkolbaşi $\mathrm{H}$. Effects of mandibular symphyseal distraction osteogenesis on mandibular structures. Am J Orthod Dentofacial Orthop. 2006 ;130:60311.

27. Gunbay T, Akay MC, Aras A, Gomel M. Effects of transmandibular symphyseal distraction on teeth, bone,and temporomandibular joint. J Oral Maxillofac Surg. 2009;67:2254-65.

28. Little RM. Stability and relapse of dental arch alignment. Br J Orthod. 1990;17:235-41.

29. Housley JA, Nanda RS, Currier GF, McCune DE. Stability of transverse expansion in the mandibular arch. Am J Orthod Dentofacial Orthop. 2003;12:288-93.

30. de Gijt JP, Vervoorn K, Wolvius EB, Van der Wal KG, Koudstaal MJ. Mandibular midline distraction: a systematic review. J Craniomaxillofac Surg. 2012;40:248-60.

31. Conley R, Legan H. Mandibular symphyseal distraction osteogenesis: diagnosis and treatment planning considerations. Angle Orthod. 2003 Feb;73:3-11

32. Pascon L, Bazert C, Bardinet E. Contribution of mandibular symphyseal distraction osteogenesis to our therapeutic strategies. J Dentofacial Anom Orthod 2016; 19:305.
33. Malkoç S1, Uşümez $\mathrm{S}$, Işeri $\mathrm{H}$. Long-term effects of symphyseal distraction and rapid maxillary expansion on pharyngeal airway dimensions, tongue, and hyoid position. Am J Orthod Dentofacial Orthop. 2007 Dec;132:769-75.

34. Lowe AA, Gionhaku N, Takeuchi K, Fleetham JA Three- dimensional CT reconstructions of tongue and airway in adult subjects with obstructive sleep apnea. Am J Orthod Dentofacial Orthop 1986;90:364-74.

35. Bacon WH, Turlet JC, Krieger J, Stierle JL. Craniofacial char- acteristics in patients with obstructive sleep apnea syndrome. Cleft Palate J 1988;25:374-8.

36. Malkoç S, Usümez S, Nur M, Donaghy CE. Reproducibility of airway dimensions and tongue and hyoid positions on lateral cephalograms. Am J Orthod Dentofacial Orthop 2005;128:513-6.

37. Jena AK., Singh SP, Utreja AK. Effectiveness of twin-block and mandibular protraction applianceIV in the improvement of pharyngeal airway passage dimensions in class II malocclusion subjects with a retrognathic mandible. Angle Orthod. 2012; 83: 728-734.

38. Brown EC, Cheng S, Mckenzie DK, Butler JE, Gandevia SC, Bilston LE. Tongue and lateral upper airway movement with mandibular advancement. Sleep 2013;36:397-404.

39. Bianchi FA, Gerbino G, Corsico M, Schellino E, Barla N, Verzè L, Ramieri G. Soft, hard-tissues and pharyngeal airway volume changes following maxillomandibular transverse osteodistraction: Computed tomography and three-dimensional laser scanner evaluation. J Craniomaxillofac Surg. 2017;45(1):47-55.

40. Guilleminault C, Li KK. Maxillomandibular expansion for the treatment of sleepdisordered breathing: preliminary result. Laryngoscope 2004;114: 893-896.

41. Conley RS, Legan HL. Correction of severe obstructive sleep apnea with bimaxillary transverse distraction osteogenesis and maxillomandibular advancement. Am J Orthod Dentofac Orthop 2006;129:283-292. 